\title{
Fourier Analysis of Written Words Focusing on Vowels: From Word Salad to Literary Works
}

\author{
Jun Shimizu \\ United Graduate School of Drug Discovery and Medical Information Sciences, \\ Gifu University, Gifu 501-1194, Japan \\ E-mail: j-shimi@fujita-hu.ac.jp \\ Kazuo Kuwata* \\ United Graduate School of Drug Discovery and Medical Information Sciences, \\ Gifu University, Gifu 501-1194, Japan \\ E-mail: kuwata@gifu-u.ac.jp
}

\begin{abstract}
We compared the population and the periodicities of vowels in texts of word salad, normal conversations and literary works using random walk representation and its Fourier transformation, in both Japanese and English. The random walk patterns of normal conversations were more coherent than those of word salads. Significant differences in characteristic periodicities were observed at around 7 and further long periodicities in word salad in Japanese, while in word salad in English they were observed at around 4. Similar analyses were performed on literary works by Japanese novelists, Yukio Mishima and Osamu Dazai. These analyses demonstrated that the random walk pattern was more spread in Dazai's novels than those by Mishima. In Dazai's novels, systematic upward deviation of the slope of the random walks was evident as a function of age, possibly representing his mental decline. The same analyses were performed for literary works by English novelists, Arthur Conan Doyle and Lucy Maud Montgomery. The results indicated that the random walk pattern was more spread in novels by Montgomery than in those by Doyle. A slight systematic upward deviation of the slope of the random walk pattern was also observed in Montgomery's novels as a function of age, possibly representing an alteration of her mental state. The random walk pattern and Fourier transform analyses of texts, wherever they are written or spoken, presented here would be useful to elucidate various stages of human mental states, and, in future, could also be implemented in social robots to assess of the mental state of a cared person.
\end{abstract}

Keywords: Signifier, Signified, Fourier Analysis, Random Walk, Vowel, Word Salad, Literary Works, Multilanguage Analysis

DOI: $10.7176 /$ JLLL/63-05

Publication date: December $31^{\text {st }} 2019$

\section{Introduction}

Lacan proposed that Freud's ideas on the functioning of the unconscious could be better understood within the context of linguistic theory (Lacan 1953; Redmond 2013; Lepoutre, et al. 2017). There might be a clear distinction between the signifier which refers to the "image" that makes up the sign, and the signified which results in creation of the signification during speech or writing. Sassure (Saussure 1959) proposed that the signified predominates over the signifier because the language is used to transfer the exact meaning, whereas Lacan argued that the signifier predominates at the level of unconsciousness and determines the logic by which symptoms are organized. In fact, incoherence in speech in schizophrenia has been reported and quantified compared to healthy control subjects (Elvevag, et al. 2007), and normative associations in the speech of individuals at familial high-risk for schizophrenia were reported to have decreased (Manschreck, et al. 2012).

At the unconsciousness level, the acoustic- or sound image of signs may be generated with a variety of randomness without clear meaning. At the consciousness level, we carefully choose the appropriate images of signs and connect them with the representation by words to form the clear meaning (Lacan 1964). However, the level of consciousness essentially varies depending on the individuals, and the differences in the unconsciousness level may partially affect the written text which represents the trajectory of word generation. In fact, during word generation, we can choose an appropriate word from multiple synonyms which possess a variety of nuances. During that selection, we may refer to the acoustic or sound image of signs developed at the unconsciousness level. Selected words may represent the logical thinking at one side, but also include the emotional aspect at the other side. Essentially the former may be independent of sound; however in the latter sound may be essential like a music. It may be difficult to remove the latter contribution even in the former process, because we connect words primarily according to the logical meaning; however it is difficult to randomize the sounds in texts.

Previously we analyzed self-similarity in various DNA sequences using Fourier transformation. We found some characteristic periodicities in these sequences and discussed the evolution of periodicity (Nagai, et al. 
2001). Human language is similar to a DNA sequence in terms of the dimensionality. Both are one-dimensional information and can be read along the time axis. DNA includes exons, introns, and other functional elements, which may correspond to nouns, verbs and other functional words such as adjectives, adverbs, pronouns, prepositions, conjunctions and interjections, respectively. Through the Fourier analyses, we found characteristic periodicities especially in the intron region (Nagai, et al. 2001).

Here we initially constructed the set theory of natural language including signifier and signified, and found an intermediate state between them. Based on the assumption of multiple layers in the word generation process, we compared the random-walk patterns of written texts and spoken languages, and applied the Fourier transform analysis to characterize the internal periodicity of vowels, essentially independently of the meaning. Initially, we compared the written texts of word salad and normal conversations in Japanese and English and found their reminiscent differences. Then, we applied these analyses to famous Japanese and English novels. In addition, we discussed the characteristics of random walks and internal periodicities, and their changes during the gradual alteration of mental state. Finally, we anticipated the application of these analytic methodologies to social robots.

\section{Methods}

\subsection{Text selection}

For word salad, in Japanese and English, we searched published literature through the Internet using keywords, "word salad", "neologism" and "hallucinations and delusions". Word salad was evident when we read the texts, which were produced by patients in schizophrenia, dementia, or other brain diseases. Sources were fully listed in the 'Word Salad in Japanese' and 'Word Salad in English' in Supplementary Data. Sentences published on the Internet in Japanese or English were randomly as normal conversation. Sources were fully listed in the Supplementary Information. Sources were fully listed in the 'Normal conversation in Japanese' and 'Normal conversation in English' in Supplementary Data. Literary works written in Japanese or English were selected from the free downloadable Internet sites. Some of the works were purchased and downloaded. Sources were fully listed in the 'Novels in Japanese' and 'Novels in English' in Supplementary Data.

2.2 Fourier transformation and statistical analysis

Using Microsoft Excel 2016 functions, FFT analyses were performed and power spectra were obtained as a function of periodicity. In addition, Microsoft Excel 2016 functions were used to perform statistical analysis (unpaired t-test) of calculated powers as a function of periodicity (statistical significance level $p<0.05$ ).

\section{Results \\ 3.1 Set theoretical formulation of word generation process}

Here we assumed that the word generation process can be schematically illustrated according to the theoretical framework developed by Sassure and Lacan, as shown in Figure 1. At the deepest unconsciousness level, the signifier might be randomly generated without explicit meaning, e.g. like a hot spring (Figure 1), and are classified as an uncountable set similar to the real number (see Appendices). In contrast, at the consciousness level, the signified might be generated by connecting generated words (signifier) to represent a certain meaning. Here meaning can be defined the rule that connect words, which is similar to the computational algorithm. The signified are one-dimensional information like a natural number and are definitely classified as a countable set (see Appendices). Here we first introduced the intermediate state (IS) between signifier and signified, and constructed a set theoretical representation of natural language covering from signifier to signified, and found the existence of an IS with a cardinality between $\chi_{0}$ and $\chi_{1}$, as shown in the Appendices. IS could construct the multiple layers from $\chi_{0}$ to $\chi_{1}$, thus signifier to signifier. Thus the continuous hypothesis $(\mathrm{CH})$ in mathematics is essentially denied in linguistics.

\subsection{Comparison of random walk patterns between word salads and normal conversations in multi-language systems}

We tentatively defined the rules of the random walk for Japanese and English as shown in Figures 2A and B, respectively, although we cannot rule out other possibilities. In our rule, the initial position of the text is always $(0,0)$ in the $(x, y)$ coordinate. In Japanese, when i-th vowel is "a", i.e. "a", "ka", "sa", "ta", "na", "ha", "ma", "ya", "la", or "wa", then the $\mathrm{i}$-th position goes up by one in the y coordinate, i.e., $\left(\mathrm{x}_{\mathrm{i}}, \mathrm{y}_{\mathrm{i}}\right)=\left(\mathrm{x}_{\mathrm{i}-1}, \mathrm{y}_{\mathrm{i}-1}+1\right)$. When i-th vowel is "i", i.e. "i", "ki", "si", "ti", "ni", "hi", "mi", or "ril", then $\left(x_{i}, y_{i}\right)=\left(x_{i-1}+1, y_{i-1}\right)$. When i-th vowel is "e", i.e. "e", "ke", "se", "te", "ne", "he", "me", or "re", then $\left(x_{i}, y_{i}\right)=\left(x_{i-1}-1, y_{i-1}\right)$. When $i-t h$ vowel is "o", i.e. "o", "ko", "so", "to", "no", "ho", "mo", "yo" or "ro", then $\left(\mathrm{x}_{\mathrm{i}}, \mathrm{y}_{\mathrm{i}}\right)=\left(\mathrm{x}_{\mathrm{i}-1}, \mathrm{y}_{\mathrm{i}-1}-1\right)$. On the other hand, when $\mathrm{i}-\mathrm{th}$ vowel is "u", i.e. "u", "ku", "su", "tu”, "nu", "hu", "mu", "yu” or "ru”, then it remains in the same position, i.e., $\left(\mathrm{x}_{\mathrm{i}}, \mathrm{y}_{\mathrm{i}}\right)=\left(\mathrm{x}_{\mathrm{i}-1}, \mathrm{y}_{\mathrm{i}-1}\right)$.

We collected 12 sets of texts both for word salad and normal conversation in Japanese and their random walk patterns are shown in Figures $3 \mathrm{~A}$ and B, respectively. Apparently, the usage of " $i$ " is dominant compared to that of "e", and those of "a" and "o" are almost comparable in both conversations. 
The average slope and standard deviation for word salad and normal conversations in Japanese were $0.25 \pm$ 0.28 and $0.25 \pm 0.15$, respectively. Thus, the random walk patterns in normal conversations were relatively coherent compared to those in word salad in terms of error, indicating that the periodicity of vowel usage was somewhat regulated in normal conversation. To confirm this, we evaluated the average fitting error and its standard deviation using the linear function and they were $5.35 \pm 1.09$ in word salad and $3.88 \pm 0.96$ in normal conversations, which indicates that the normal conversations are well organized and coherent in terms of vowel usage and frequency compared to those in word salad.

To find the characteristic frequency in the random walk, we performed Fourier analysis for word salad and normal conversation. Their power spectra are shown in Figures 4A-J. Then, we calculated the mean difference and its standard deviation in power spectra between word salad and normal conversation as a function of periodicity. Although the results are shown in Figures $4 \mathrm{~K}-\mathrm{O}$, in order to detect the specific frequency, we performed a statistical test ( $\mathrm{t}$-test) to compare word salad $(\mathrm{n}=12)$ and normal conversation $(\mathrm{n}=12)$ groups, and found several characteristic periodicities shown in Figures 4P-T. Interestingly, significantly different frequencies $(\mathrm{P}<0.01)$ between word salad and normal conversation were $(\mathrm{a}): 7.6,11.1 ;(\mathrm{i}): 6.9,8.1 ;(\mathrm{u}): 7.95,60.2 ;(\mathrm{e}): 7.59$, 8.16, 18.1; and (o); 8.2, 13.1. Thus, in Japanese, fundamental periodicities around 7- 8 and further long periodicities are incorporated in normal conversations compared to word salad.

To investigate whether the above observation is universal to other languages, we collected 13 word salad texts and 13 normal conversation texts in English. In English, pronunciation is somewhat context dependent, and vowel usage is not always true to written texts. However, we found similar patterns, as shown in Figures 5A and B. Apparently, the usage of "o" is dominant compared to that of " $\mathrm{a}$ ", and those of " $\mathrm{e}$ " and " $\mathrm{r}$ " are almost comparable in both conversations in English.

We plotted random walk patterns in Figures $5 \mathrm{~A}$ and $\mathrm{B}$, according to the rule in Figure $2 \mathrm{~B}$. Since the vowel structure is strongly dissimilar between Japanese and English, we tried several combinations of vowel axes in English and we found that the combination in Figure 2B yields similar patterns to those in Japanese (see Figures $3 \mathrm{~A}$ and $\mathrm{B})$. The average slope and standard deviation for word salad and normal conversation are $0.33 \pm 1.13$ and $0.36 \pm 0.30$, respectively. Thus, the walking patterns in normal conversation were relatively coherent compared to those in word salad also in English, indicating that the periodicity of vowel usage was somewhat regulated in normal conversation in English. In fact, the average fitting error and standard deviation using the linear function are $3.21 \pm 1.68$ in word salad and $2.56 \pm 0.65$, showing the normal conversations are well organized in terms of vowel usage and frequency, while word salad are less regulated and more dispersed.

To clarify the characteristic periodicities in the random walks in English, we performed Fourier analysis for word salad and normal conversation, as shown in Figures 6A-J. Then, we found several characteristic periodicities. We calculated the mean difference and the standard deviation in power between word salad and normal conversation as a function of periodicity. We performed the statistical test ( $\mathrm{t}$-test) between word salad $(n=13)$ and normal conversation $(n=13)$ groups and found several characteristic periodicities, as shown in Figures 6P-T. Interestingly, significantly different frequencies $(\mathrm{P}<0.01)$ between word salad and normal conversation in English were (a): no characteristic periodicity; and (e): 3.71, 14.2; (i):no characteristic periodicity; (o); 4.12; (r) no characteristic periodicity. Thus in English, fundamental periodicities were predominant around 3-4 and further long periodicity is also incorporated in the normal conversations rather than in the word salad.

\subsection{Comparison of random walk patterns in Japanese novels}

We analyzed the representative literary works accomplished in Japanese and English. For Japanese, we selected 12 novels written by Yukio Mishima who committed suicide by hara-kiri at 1970, and 12 novels by Osamu Dazai who committed suicide with a lover at 1948.

We plotted the random walk patterns of Mishima and Dazai in Figures 7A and B, respectively, according to the rule given in Figure 2A. Their patterns were somewhat coherent and well organized. The average slope and standard deviation for Mishima and Dazai were $-0.042 \pm 0.07$ and $-0.00028 \pm 0.12$, respectively. Thus, the walking patterns in Mishima's works were relatively coherent compared to those in of Dazai's works, which indicates that the internal periodicity of vowel usage was strictly controlled by Mishima. In fact, the average fitting error and standard deviation obtained using the linear function were $31.9 \pm 13$. 8 for Mishima and 33.9 \pm 14.0 for Dazai, demonstrating Mishima's novels were well organized in terms of vowel usage and its frequency, while those of Dazai were less regulated and more dispersed. We ploted the slope of random walk patterns as a function of the novelist age in Figure 7C. As shown the slope in Mishima was nearly constant with a slight downward trend indicating that the usage of "o" was slightly predominant throughout his life, while for Dazai the usage of "a" increased with increase of age. This may suggest that Mishima's novels were regulated logically according to his strong ideology, while those of Dazai were driven by the author's state of mind, which may be dependent on age.

To clarify the characteristic frequencies of the random walks, we performed Fourier analysis on Mishima's 
and Dzai's works and obtained the power spectra, as shown in Figures 8A-J. We then calculated the mean difference and its standard deviation in power between Mishima and Dazai as a function of periodicity. We performed the statistical t-test between word salad $(n=12)$ and normal conversation $(n=12)$ groups. We found several characteristic periodicities, which shown in Figures 8P-T. Interestingly, the following significantly different frequencies $(\mathrm{P}<0.01)$ were found between Mishima and Dazai; (a): 7.63, 11.0; (i): 6.93, 8.09; (u):7.95, $60.2 ;$ (e):7.60, $18.1 ;(\mathrm{o}) ; 8.22,13.5$. Therefore, for Dazai, the fundamental periodicities were predominant around 7 and longer periodicities were also incorporated by Dazai.

\subsection{Comparison of random walk patterns in English novels between Arthur Conan Doyle and Lucy Maud Montgomery}

We also analyzed representative literary works in English. We selected 13 novels by Arthur Conan Doyle who died in 1930, and 10 novels by Lucy Maud Montgomery who committed suicide in 1942 due to depression.

The random walk patterns are in Figures $9 \mathrm{~A}$ and $\mathrm{B}$, according to the rule in Figure $2 \mathrm{~B}$. The patterns are coherent and well organized. The average slope and standard deviation for Doyle and Montgomery were $0.41 \pm$ 0.13 and $0.39 \pm 0.11$, respectively. Thus, their walking patterns were similar. However, the average fitting error and standard deviation obtained using the linear function were $31.1 \pm 12$. 2 for Doyle and $35.9 \pm 19.3$ for Montgomery, which demonstrates that Doyle's novels were well organized in terms of vowel usage and frequency, while those of Montgomery were less regulated and more dispersed. We plotted the slope of the random walk patterns as a function of author age in Figures 9C and D. As can be seen, the slope in Doyle shows a slight downward trend, while that of Montgomery showed a slightly increasing trend, similar to that of Dazai shown in Figure 7D. This suggested that the usage of ' $\mathrm{e}$ ' increases slightly increasing relative to ' $\mathrm{r}$ ' throughout Montgomery's life. This may suggest that novels of Dazai and Montgomery were primarily driven by the depressive state of mind over time.

To clarify the characteristic frequencies in the random walks, we performed Fourier analysis for Montgomery's and Doyle's literatures and obtained the power spectra, as shown in Figures 10A-J. We calculated the mean difference and its standard deviation in power between Montgomery and Doyle as a function of periodicity. We performed the statistical test (t-test) and found several characteristic periodicities shown in Figures 10P-T. Interestingly, significantly different frequencies $(\mathrm{P}<0.01)$ between Montgomery and Doyle were (a): 3.67, 13.7; (e): 3.88, 14.2; (i):8.00, 22.3; (o):4.08, 14.6 and (r): 4.86, 8.77. Thus in Montgomery, fundamental periodicities were predominant around 4 and further long periodicity was incorporated in Montgomery.

\section{Discussion}

\subsection{Representation by one-dimensional space}

Human languages including natural languages, mathematical languages, programming languages, and genetic information are essentially represented by one dimensional arrays of the elements i.e., characters. In contrast, the human imagination can spread into multiple dimensions. However, any multidimensional space can be essentially equivalent to a one-dimensional space in terms of its cardinality or density. Hence, one-dimensional information could be the most basic form of information for our brain. Random or regular arrangement of characters, or degree of regularity determines the characteristics of the one-dimensional space set.

\subsection{Symmetries in vowel usage}

The random walk pattern in Japanese showed that the usage of "a" and "o" were almost equivalent, while the usage of "i" was predominant compared to that of "e". In word salad, usage of each vowel seemed to be distributed relatively randomly. In contrast, in English, "e" and "r" were comparable, and "o" was predominant compared to "a" in normal conversations, whereas in word salad, usage of each vowel seemed to be relatively randomly distributed. Random distribution of vowels in word salad was common for Japanese and English (Figures 3 and 5). This observation was consistent in that word salad partially represents signifier and vowel usages were randomly distributed, while normal conversation represents signified, and vowel usages were more or less regulated.

\subsection{Entanglement of signifier and signified}

Here we provided a proof that, by definition, signifier is essentially uncountable and the signified is countable (See Appendices). In unconsciousness, we generate words at a signifier level. Word salad may be close to the signifier rather than the signified. In consciousness, we select and connect words to represent the meaning at a signified level (Figure 1) forming normal conversation in which vowel usage is also regulated in terms of its probability and frequency, as described above. At the signified level, we select a word in order to represent a meaning. This process is similar to the regulation by a computational algorithm. However, for example, multiple synonyms exist to represent similar meaning, which results in a space of uncertainty in which the signifier 
remains partially unregulated even in the signified. This uncertainty introduces systematic deviation of regulated walk to random walk patterns in signified, which reflects the emotional aspect of the unconscious level in signified. This was demonstrated by the age dependence of the slope of the random walk in the literature authored by Dazai and Montgomery, which may reflect depression leading to the suicide.

\subsection{Characteristic periodicities}

Fourier transform analyses revealed the existence of basic periodicities through all the vowels around 7 to 8 in normal Japanese conversation. Interestingly, the format of the famous Japanese "Haiku" is 5, 7, and 5, and that of "Waka" is 5, 7, 5, 7 and 7. Thus, Japanese is considered to possess the internal periodicities, 5 and 7. However, by focusing on the vowel, we were able to detect the internal periodicity, 7, as described above. In addition, we observed further long range periodicities, i.e., 11 in "a", 21 in "i", 13 in " 0 ", 18 in "e", and 60 in "u. These longrange periodicities could be explained by the combinations of 5 and 7 , which yields numbers close to these long periodicities, i.e., $5+5=10,5+7=12,5+7+5=17$ and $(5+7+5+7+7) \times 2=62$.

In contrast, in English, characteristic periodicity is around 4 and long-range periodicity was observed only around 14. This demonstrates that in English pronunciation does not exactly correspond to the written characters. In normal conversations, approximately four characters representing vowel typically form basic periodicities in normal conversation in English.

\subsection{Differences in characteristic periodicities between literary works}

We observed statistically significant differences between Japanese literature authored by Mishima and Dazai. Their characteristic periodicities are basically around 7 and further long range periodicities are 28, 17 and 11 in "a", 107, 47 in "I", 14 in "o", 27, 22, $\underline{18}, 15$ and 10 in "e", and $\underline{60}, 30,23,19$ and 12 in "u", which basically includes those between word salad and normal conversation in Japanese, and further long-range periodicities. Thus, the differences in periodicities between Mishima and Dazai lies in long-range periodicities. Although the details remain elusive, these differences may originate from those in vowel usage at the signifier level.

\subsection{Meaning of signified}

peech structure and its randomness in schizophrenia has been analyzed (Mota, et al. 2017). In addition, the language analyses of schizophrenia has been performed (Kuperberg 2010a, b). The differences in language between schizophrenia patients and normal subjects were not well defined in their semantic structures nor meaningfulness.

Signified is constructed based on the signifier in order to represent the meaning. Meaning can be generated by reducing the uncountable number of word combinations to countable combinations (see Appendices). However, as described above, we may still have an infinite number of meanings. Thus, population analysis of words might be inappropriate. We need to develop the meaning independent analysis methodology. Here we proposed an analysis that is apparently independent of meaning.

\subsection{Analysis by other computational models}

Various meaning models, such as the latent semantic analyses(Elvevag, et al. 2007; Holshausen, et al. 2014; Rezaii, et al. 2019), which was applied to schizophrenia to analyze the incoherence of speech. They used 37,651 text samples with 92,408 unique words and matrices of 300 dimensions to perform SVD analyses. The basic question is whether it is possible to differentiate the coherence and the incoherence of speech in terms of meaning by the usage population. Rare usage or rare combination of words do not necessarily mean the incoherence in terms of meaning. We should remember that the novel scientific findings were explained only by the novel combinations of ever-existing words. We need to develop an effective analytical methodology for meaning analysis, before proceeding the big data analysis. Correctness of meaning is not supported by the usage population, but is rather connected to the existence of any algorithm which can generate words (signified). Because there exists uncertainty as described above, we need to carefully represent the procedure from signifier to signified, i.e., uncountable to countable, and rank the degree of coherence, which is independent of the "meaning model."

Computational linguistic analysis on verbal fluency has been conducted using an automated tool, CoVec (Pauselli, et al. 2018) to detect the speech disorganization, such as derailment and tangentiality in schizophrenia. In this analysis, coherence was defined as the average similarity (norm) of each word to other words. Statistical tests (such as ANOVA) on the calculated norm was performed for pairwise comparison between control subjects and patients. However, the low similarity defined above does not necessarily mean any disorganization or abnormality in speech. Rare combinations of words with clear logical connection does not mean derailment nor tangentiality. Logical connections of words may not allow such population analyses, because completely new word connections, novel concepts or creative works must originate from a zero matrix element. Furthermore, more important linguistic aspects, such as semantic structures, discourse organization, as well as acoustic 
characteristics (Foltz, et al. 2016) are still missing, and it is essentially questionable whether they could be further characterized using natural language processing (NLP) and machine learning (ML) techniques (Bedi, et al. 2015). The proposed method presented can address the acoustic characteristics and further semantic organization such as signifier and signified, as described above.

\subsection{Critical differences between Japanese and English in terms of vowel organization}

Although Figs. 3 and 4 exhibit similar behaviors, characteristic periodicities are different significantly between Japanese and English. In Japanese, fundamental periodicity lies around 7 and longer periodicities are further observed, while in English fundamental periodicity is about 4, and longer periodicities are quite sparse. The fundamental acoustic structure of Japanese is that Japanese characters consist of either a vowel or a consonant plus a vowel and all characters include one vowel that belongs to one of five groups, i.e. "a", "i", "u", "e”, “o". In English, consonants and vowels are essentially distributed independently and pronunciation depend both the characters and contexts. Thus, our approach may be more suitable to the analysis of Japanese than English

\subsection{Further developments}

Recently, various social robots (Cruz-Sandoval and Favela 2019; Fiske, et al. 2019) were developed for therapeutic applications in mental health services, i.e., in psychiatry, psychology, and psychotherapy, such as dementia care (Cruz-Sandoval and Favela 2019) and autism spectrum disorder (Kumazaki, et al. 2019) . The proposed method is quite simple and easily implemented to various social robots. The random walk pattern analysis of the conversation with a human or a robot may exhibit the detailed level of consciousness, as shown in Figures 3, 5, and 7. The characteristic periodicities may represent a decline of the mental state that is hardly noticed by an individual subjects nor other people. With these implementations, it is expected that, in future, a social robot will be able to enumerate these parameters and provide patients with adequate expressions.

\section{Conclusion}

The random walk and Fourier transform analyses of human languages focusing on vowels presented here are quite useful for elucidating various stages of mental states. These methods are essentially independent of the meaning of the written or spoken words, and thus the relevant algorithms presented here could be easily implemented in social robots to assess of the mental state of a cared person. In near future, we will construct such a social robot which can communicate with people sensing his or her emotional sign, and offer an adequate advice or appropriate words.

\section{Supplementary Material}

6.1 Signifier is an infinite sequence

Proof: If the number of words in a signifier was $n$, then we can add a word at its tail and then the number of words become $n+1$. We can repeat this process in a recursive manner, since the meaning of the sequence does not matter.

\subsection{Signifier constructs an uncountable set}

Proof: Here we consider the set $\mathrm{S}$ of all infinite sequences of signifier. Let us assume $\mathrm{S}$ is countable. Then, all its elements can be written as $s_{1}, s_{2}, \ldots, s_{n}$ (Table 1). A sequence $s$ is constructed by choosing the $1^{\text {st }}$ word as different than $\mathrm{w}_{11}$, i.e., $\mathrm{w}^{11}$, the second word as different than $\mathrm{w}_{22}$, i.e. $\mathrm{w}^{22}, \ldots$ and, in general, nth word as different than $\mathrm{w}_{\mathrm{nn}}$, i.e., $\mathrm{w}^{\mathrm{nn}}$. In this construction, $\mathrm{s}$ differs from each $\mathrm{s}_{\mathrm{n}}$, because their $\mathrm{n}^{\text {th }}$ word differs. Hence, $\mathrm{s}$ does not belong to the set S. However, this contradicts $\mathrm{s}$ being an element of S, since $\mathrm{s}$ is apparently the infinite sequence of signifiers. This contradiction implies that the original assumption is false. Therefore, $\mathrm{S}$ is uncountable.

Table 1: Diagonal Method

\begin{tabular}{|c|c|c|c|c|c|c|}
\hline $\mathrm{s}_{1}=$ & $\mathrm{W}_{11}$ & $\mathrm{~W}_{12}$ & $\mathrm{~W}_{13}$ & $\mathrm{~W}_{14}$ & $\mathrm{~W}_{15}$ & $\ldots$ \\
\hline $\mathrm{S}_{2}=$ & $\mathrm{W}_{21}$ & $\mathrm{~W}_{22}$ & $\mathrm{~W}_{23}$ & $\mathrm{~W}_{24}$ & $\mathrm{~W}_{25}$ & $\ldots$ \\
\hline $\mathrm{S}_{3}=$ & $\mathrm{W}_{31}$ & $\mathrm{w}_{32}$ & $\mathrm{~W}_{33}$ & $\mathrm{~W}_{34}$ & $\mathrm{~W}_{35}$ & $\ldots$ \\
\hline $\mathrm{S}_{4}=$ & $\mathrm{W}_{41}$ & $\mathrm{~W}_{42}$ & $\mathrm{~W}_{43}$ & $\mathrm{~W}_{44}$ & $\mathrm{~W}_{45}$ & $\ldots$ \\
\hline $\mathrm{S}_{5}=$ & $\mathrm{W}_{51}$ & $\mathrm{~W}_{52}$ & $\mathrm{~W}_{53}$ & $\mathrm{~W}_{54}$ & $\mathrm{~W}_{55}$ & $\ldots$ \\
\hline $\mathrm{S}_{6}=$ & $\mathrm{W}_{61}$ & $\mathrm{w}_{62}$ & $\mathrm{w}_{63}$ & $\mathrm{w}_{64}$ & $\mathrm{~W}_{65}$ & $\ldots$ \\
\hline$\ldots$ & $\ldots$ & $\ldots$ & $\ldots$ & $\ldots$ & $\ldots$ & $\ldots$ \\
\hline
\end{tabular}

6.3 Signified is an infinite sequence.

Proof: If the number of words in a signified was n, we can add a meaningful word or meaningful sentence at its tail. Then the number of words becomes $n+1$. We can repeat this process recursively. 
6.4 Signified does not construct an uncountable set.

Proof: We consider the set $\mathrm{T}$ of all infinite sequences of signified. Let us assume $\mathrm{T}$ is countable. Then all its elements can be written as $t_{1}, t_{2}, \ldots, t_{n}$. However, in signified, whether a sequence of words, $w_{11}, w_{22}, \ldots w_{n n}$ would retain any meaning is not guaranteed. Although we can select the nth word different as $\mathrm{w}_{\mathrm{nn}}$ to create some meaning. All the words do not necessarily have synonyms or antonyms and some words cannot be substituted with different words in order to maintain the grammatical structure. Thus, $\mathrm{T}$ fails to generate contradiction and may still be countable.

6.5 Intermediate state (IS) between signifier and signified is an infinite sequence.

Here we consider an IS between signifier and signified.

Proof: If the number of words in a signified was n, we can add a meaningful word or meaningful sentence at its tail. Then the number of words becomes $n+1$. We can repeat this process in a recursive manner.

6.6 IS constructs the cardinality between $\chi_{0}$ and $\chi_{1}$.

Let us assume $I$ is countable. Then, all its elements can be written as $i_{1}, i_{2}, \ldots, i_{n}$. In IS, the meaning of the sequence of words may not be strictly preserved. A sequence of words, $\mathrm{w}_{11}, \mathrm{w}_{22}, \ldots \mathrm{w}_{\mathrm{nn}}$ would have meaning when we select the $n$th word as different than $\mathrm{w}_{\mathrm{nn}}$ to create any meaning. In an IS, grammatical structure may not be strictly preserved, and the meaning may not be precisely organized. Therefore some $\mathrm{w}_{\mathrm{iii}} \mathrm{S}$ should not be altered to gain some meaning; however, others may be replaced. As shown in Table 2, when $w_{i i}$ to $w_{i(i+j)} w_{e r e}$ irreplaceable, we would use $w_{(i+1)(i+j+1)}$ for the word next to $w_{i i}$ instead of $w_{(i+1)(j+1)}$. The shift of $j$ words at certain regions constructs the off-diagonal method for the disproval of the continuum hypothesis in natural language. Then we can now construct the cardinality between $\chi_{0}$ and $\chi_{1}$, as follows:

Table 2: Off-diagonal Method

\begin{tabular}{|c|c|c|c|c|c|c|c|c|c|c|}
\hline$s_{1}=$ & $\mathrm{W}_{11}$ & $\mathrm{~W}_{12}$ & $\ldots$ & $\mathrm{w}_{1 \mathrm{j}}$ & $\mathrm{w}_{1(\mathrm{j}+1)}$ & $\ldots$ & & & & \\
\hline $\mathrm{S}_{2}=$ & $\mathrm{W}_{21}$ & $\mathrm{~W}_{22}$ & $\ldots$ & $\mathrm{w}_{2 \mathrm{j}}$ & $\mathrm{W}_{2(\mathrm{j}+1)}$ & $\ldots$ & & & & \\
\hline$\ldots$ & $\ldots$ & $\ldots$ & $\ldots$ & $\ldots$ & $\ldots$ & $\ldots$ & & & & \\
\hline $\mathrm{S}_{\mathrm{i}}=$ & $\mathrm{W}_{\mathrm{i} 1}$ & $\mathrm{~W}_{\mathrm{i} 2}$ & $\ldots$ & $\mathrm{W}_{\mathrm{ii}}$ & $\mathrm{W}_{\mathrm{i}(\mathrm{i}+1)}$ & $\ldots$ & $W_{i(i+j)}$ & & & \\
\hline $\mathrm{S}_{\mathrm{i}+1}=$ & $\mathrm{W}_{(\mathrm{i}+1) 1}$ & $\mathrm{~W}_{(\mathrm{i}+1) 2}$ & $\ldots$ & $\mathrm{W}_{(\mathrm{i}+1) \mathrm{i}}$ & $\mathrm{W}_{(\mathrm{i}+1)(\mathrm{i}+1)}$ & $\ldots$ & & $\mathrm{W}_{(\mathrm{i}+1)(\mathrm{i}+\mathrm{j}+1)}$ & & \\
\hline $\mathrm{S}_{\mathrm{i}+2}=$ & $\mathrm{W}_{(\mathrm{i}+2) 1}$ & $\mathrm{~W}_{(\mathrm{i}+2) 2}$ & $\ldots$ & $\mathrm{W}_{(\mathrm{i}+2) \mathrm{i}}$ & $\mathrm{W}_{(\mathrm{i}+2)(\mathrm{i}+1)}$ & $\ldots$ & & & $\ldots$ & \\
\hline$\ldots$ & $\ldots$ & $\ldots$ & $\ldots$ & $\ldots$ & $\ldots$ & $\ldots$ & & & & \\
\hline
\end{tabular}

We categorized the IS into the following three groups.

(1) The number of replaceable words is finite. In this case, the IS can generate the contradiction; thus the IS is uncountable.

(2) The number of irreplaceable words $\left(\sum_{i} j\right)$ is finite. In this case, the IS cannot generate the contradiction; thus IS is countable $\left(\chi_{0}\right)$.

(3) The numbers of replaceable words and irreplaceable words are both infinite. In this case, if the IS is assumed to be countable, it is countable. If the IS is uncountable, it is uncountable. We cannot determine whether the IS is countable or uncountable. Thus the IS constructs the cardinality between $\chi_{0}$ and $\chi_{1}$.

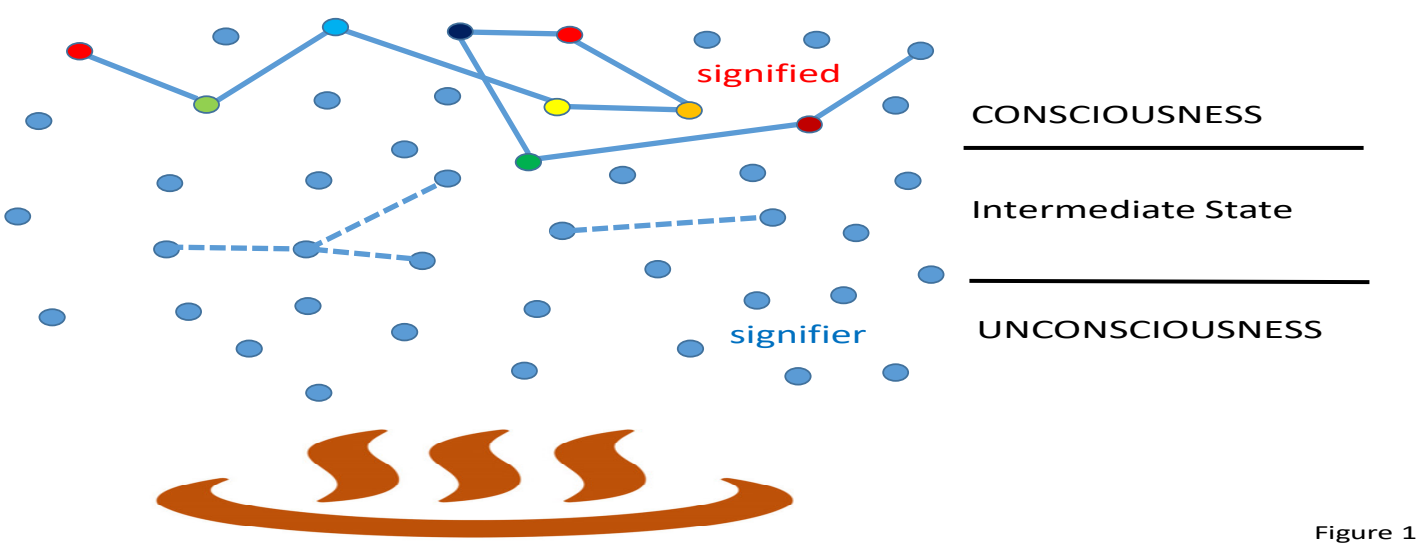

Figure 1. A model of word generation process in human. In a unconsciousness level shown at the bottom, words production occurred randomly without logical connection. Lacan and Sassure termed this process 'signifier'. In a consciousness level, generated words are selected and logically connected to represent the meaning. This process is termed 'signified'. In contrast, there may exist an intermediate state between signifier and signified. 
A

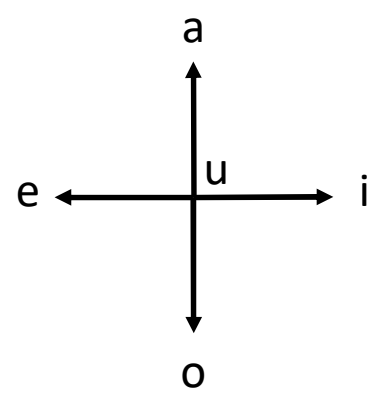

$\mathrm{B}$

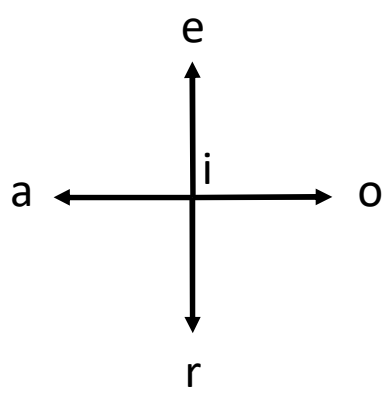

Figure 2

Figure 2. (A) The rule of random walk in Japanese, in which the initial position of the text is always $(0,0)$ in the (x, y) coordinate. When i-th vowel is "a", i.e. "a", "ka", "sa", "ta", "na", "ha", "ma", "ya", "la", or "wa", then the $\mathrm{i}$-th position goes up by one in the y coordinate, i.e., $\left(\mathrm{x}_{\mathrm{i}}, \mathrm{y}_{\mathrm{i}}\right)=\left(\mathrm{x}_{\mathrm{i}-1}, \mathrm{y}_{\mathrm{i}-1}+1\right)$. When $\mathrm{i}$-th vowel is "i", i.e. " $\mathrm{i}$ ", "ki", "si", "ti", "ni", "hil", "mi", or "rì", then $\left(x_{i}, y_{i}\right)=\left(x_{i-1}+1, y_{i-1}\right)$. When $i-t h$ vowel is "e", i.e. "e", "ke", "se", "te", "ne", "he", "me", or "re", then $\left(x_{i}, y_{i}\right)=\left(x_{i-1}-1, y_{i-1}\right)$. When $i-t h$ vowel is "o", i.e. "o", "ko", "so", "to", "no", "ho", "mo", "yo" or "ro", then $\left(\mathrm{x}_{\mathrm{i}}, \mathrm{y}_{\mathrm{i}}\right)=\left(\mathrm{x}_{\mathrm{i}-1}, \mathrm{y}_{\mathrm{i}-1}-1\right)$. On the other hand, when i-th vowel is "u", i.e. "u", "ku", "su", "tu", "nu", "hu", "mu", "yu" or "ru", then it remains in the same position, i.e., $\left(\mathrm{x}_{\mathrm{i}}, \mathrm{y}_{\mathrm{i}}\right)=\left(\mathrm{x}_{\mathrm{i}-1}, \mathrm{y}_{\mathrm{i}-1}\right)$. (B) The rule of random walk in English, in which the initial position of the text is always $(0,0)$ in the $(x, y)$ coordinate. When ith vowel is "e", then the $\mathrm{i}$-th position goes up by one in the y coordinate, i.e., $\left(\mathrm{x}_{\mathrm{i}}, \mathrm{y}_{\mathrm{i}}\right)=\left(\mathrm{x}_{\mathrm{i}-1}, \mathrm{y}_{\mathrm{i}-1}+1\right)$. When $\mathrm{i}$-th vowel is " 0 ", , then $\left(x_{i}, y_{i}\right)=\left(x_{i-1}+1, y_{i-1}\right)$. When $\mathrm{i}$-th vowel is "a", then $\left(x_{i}, y_{i}\right)=\left(x_{i-1}-1, y_{i-1}\right)$. When $i$-th vowel is " $r$ ", then $\left(x_{i}, y_{i}\right)=\left(x_{i-1}, y_{i-1}-1\right)$. On the other hand, when $i-t h$ vowel is " $i$ ", then it remains in the same position, i.e., ( $x_{i}$, $\left.\mathrm{y}_{\mathrm{i}}\right)=\left(\mathrm{x}_{\mathrm{i}-1}, \mathrm{y}_{\mathrm{i}-1}\right)$.

A

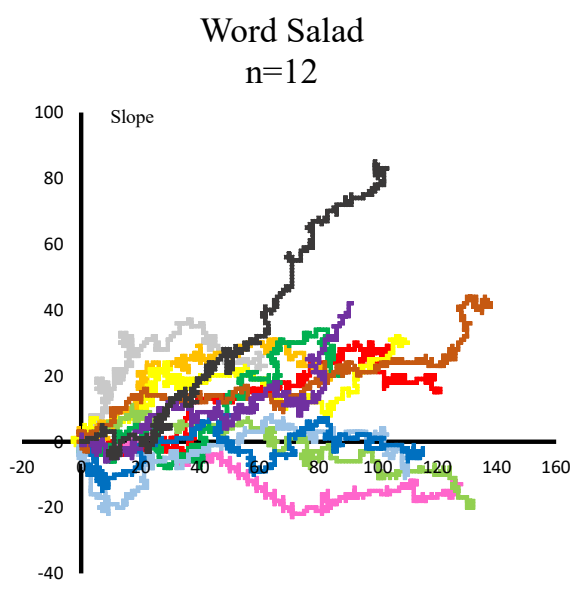

B

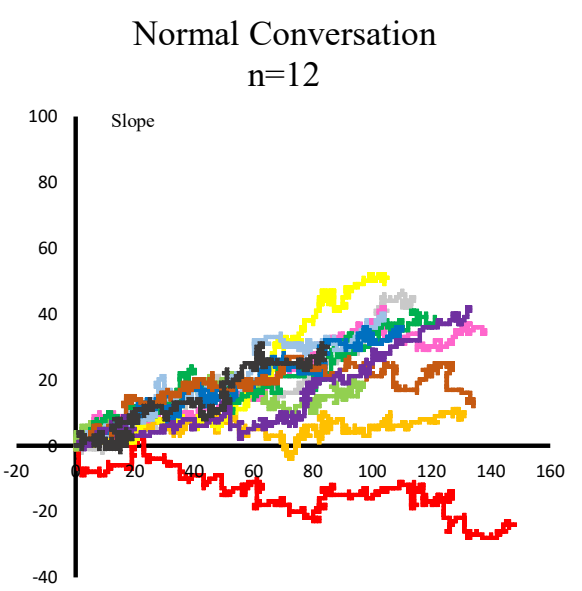

Figure 3

Figure 3. (A) Random walk patterns of word salads in Japanese. See text for the statistical analyses. (B) Random walk patterns of normal conversations in Japanese. See text for the statistical analyses. 
$\mathbf{A}$

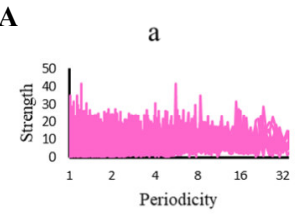

F

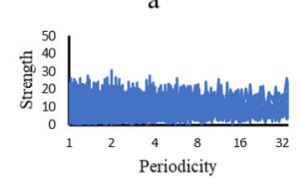

$\mathbf{K}$

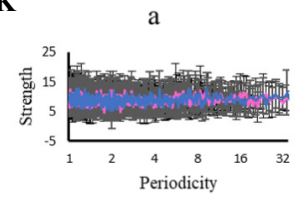

$\mathbf{P}$

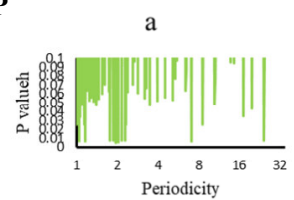

B

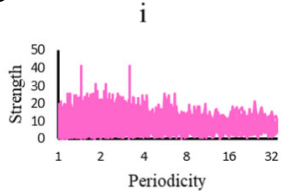

G

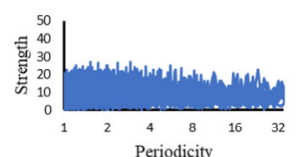

$\mathbf{L}$

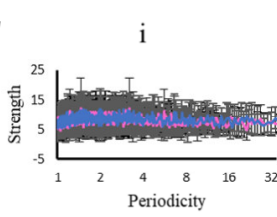

$\mathbf{Q}$

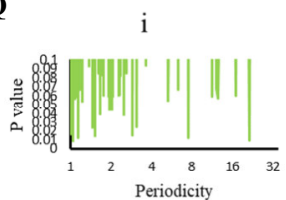

C

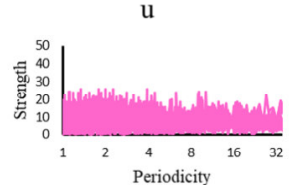

$\mathbf{H}$

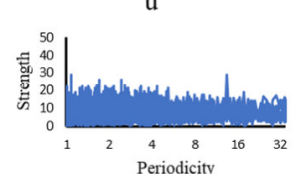

M

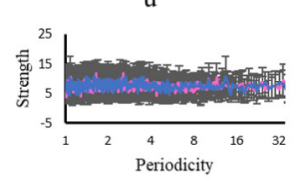

$\mathbf{R}$

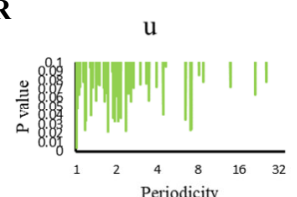

D

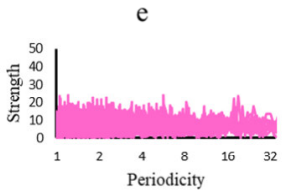

I

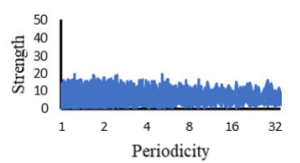

$\mathbf{N}$

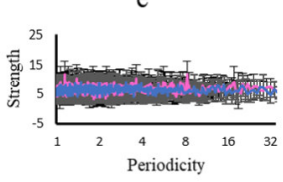

S

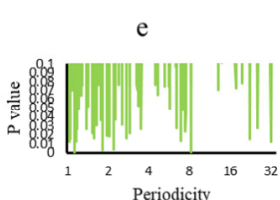

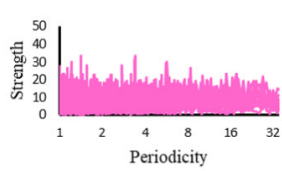

$\mathbf{J}$

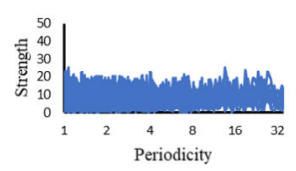

O

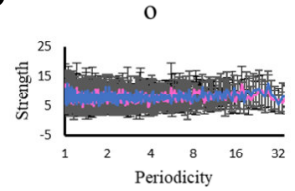

T

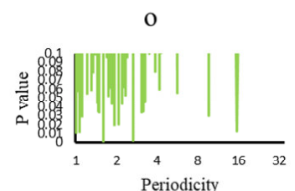

Figure 4. Fourier transform analyses of word salads and normal conversations in Japanese, and its comparison. (A-E) Fourier transform of the trajectories 'a', ' $i$ ', ' 'u', 'e' and 'o' in word salads. Powers are plotted as a function of periodicity. (F-J) Fourier transform of the trajectories ' $a$ ', ' $i$ ', ' $u$ ', 'e' and ' $o$ ' in normal conversations. Powers are plotted as a function of periodicity. (K-O) Differences in power as a function of periodicity between word salads and normal conversations. (P-T) P values of t-test between word salads and nor mal conversations as a function of periodicity.

A

\section{Word Salad $\mathrm{n}=13$}

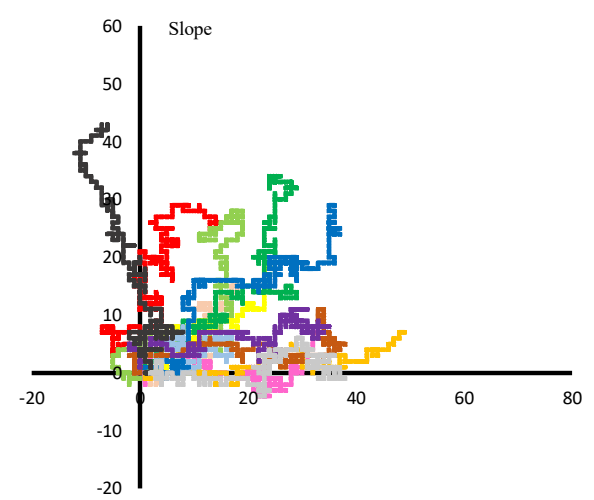

B

Normal Conversation $\mathrm{n}=13$

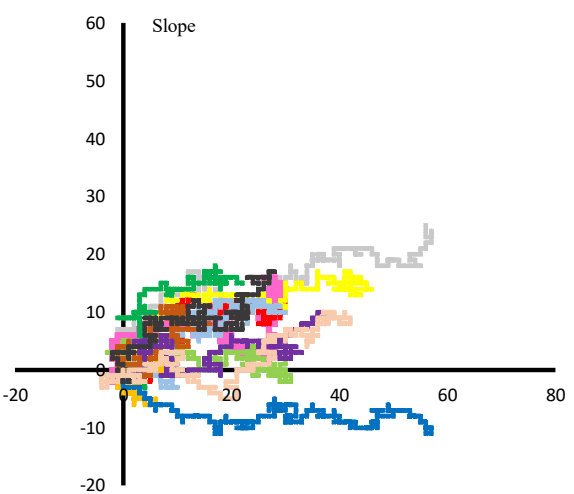

Figure 5

Figure 5. (A) Random walk patterns of word salads in English. See text for the statistical analyses. (B) Random walk patterns of normal conversations in English. See text for the statistical analyses. 
$\mathbf{A}$

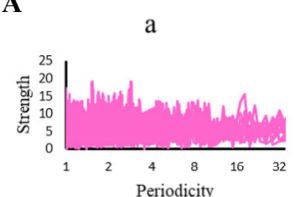

F

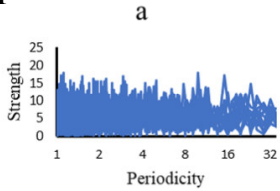

K

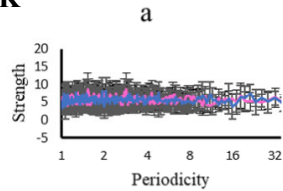

$\mathbf{P}$

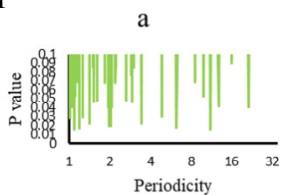

B

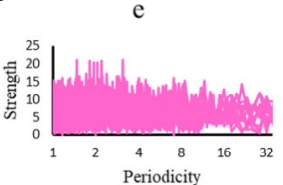

G

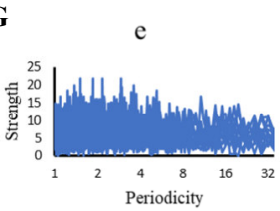

$\mathbf{L}$

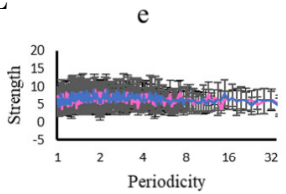

Q

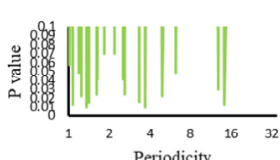

C

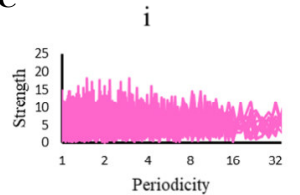

H

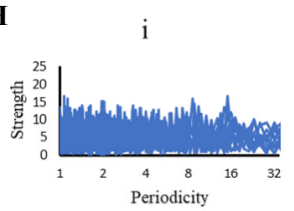

M

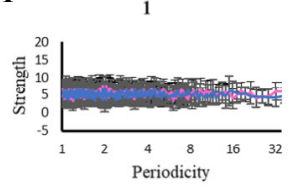

$\mathbf{R}$

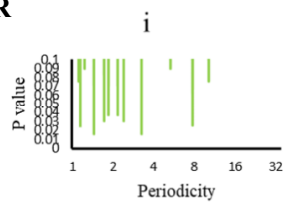

D

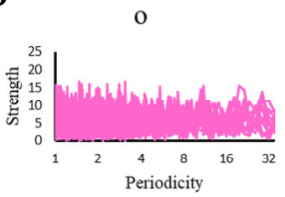

I

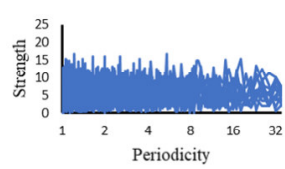

N

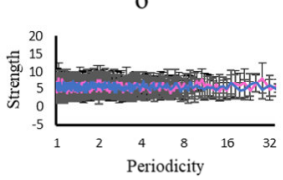

S

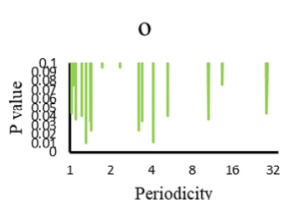

$\mathbf{E}$

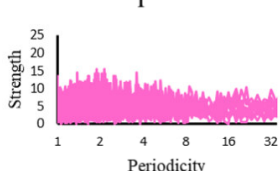

J

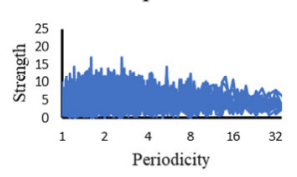

O

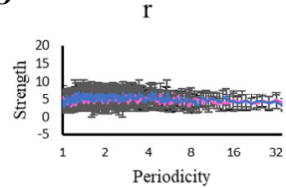

T

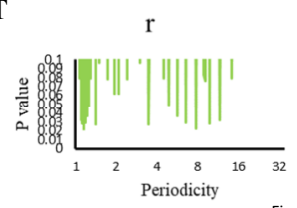

Figure 6. Fourier transform analyses of word salads and normal conversations in English, and its comparison. (A-E) Fourier transform of the trajectories ' $a$ ', ' $e$ ', 'o', 'i' and ' $r$ ' in word salads. Powers are plotted as a function of periodicity. (F-J) Fourier transform of the trajectories ' $a$ ', 'e', 'o', 'i' and ' $r$ ' in normal conversations. Powers are plotted as a function of periodicity. (K-O) Differences in power as a function of periodicity between word salads and normal conversations. (P-T) P values of t-test between word salads and nor mal conversations as a function of periodicity.

A

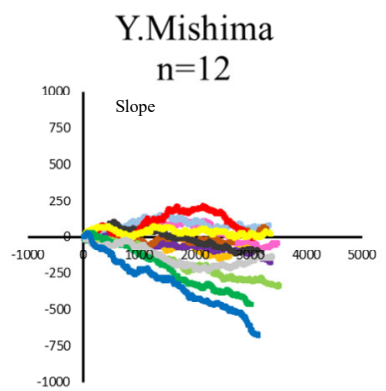

C

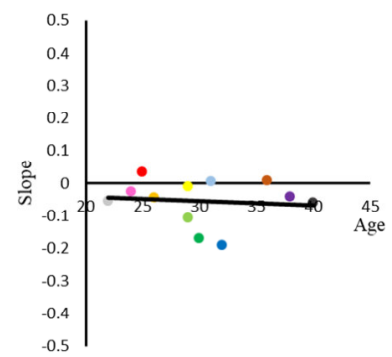

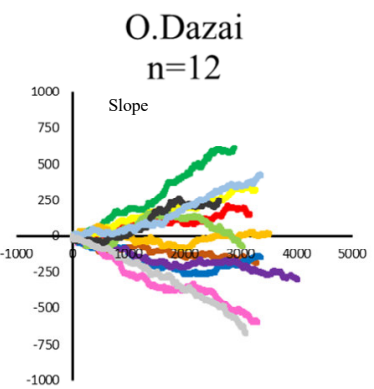

D

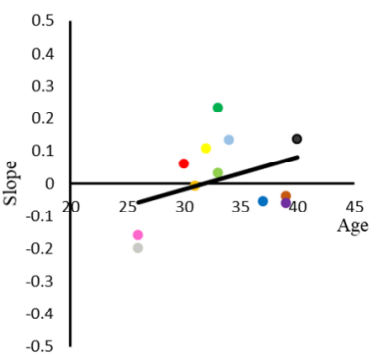

Figure 7

Figure 7. (A) Random walk patterns of literatures by Yukio Mishima in Japanese. See text for the statistical analyses. (B) Random walk patterns of literatures by Osamu Dazai in Japanese. See text for the statistical analyses. (C) Slope of random walk pattern obtained by the linear fit is plotted as a function of the age at which the literature was written by Mishima. (D) Slope of random walk pattern obtained by the linear fit is plotted as a function of the age at which the literature was written by Dazai. 


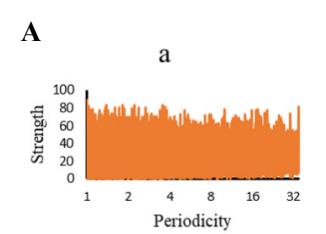

F

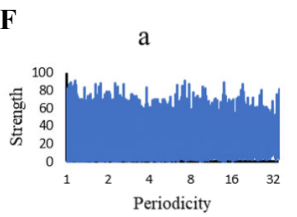

$\mathbf{K}$

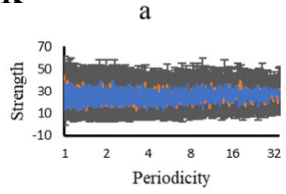

$\mathbf{P}$

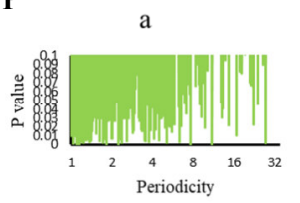

B

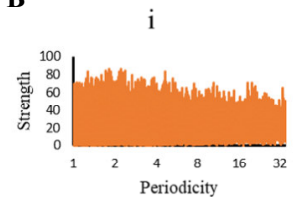

G

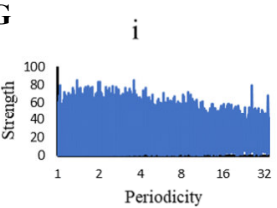

$\mathbf{L}$

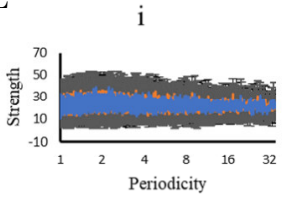

$\mathbf{Q}$

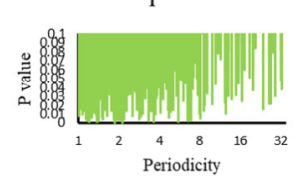

C

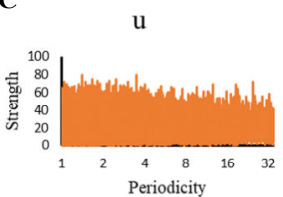

H

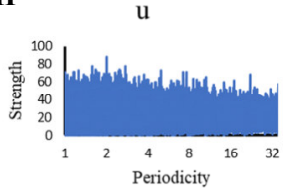

M

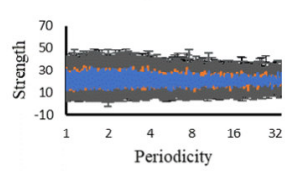

R

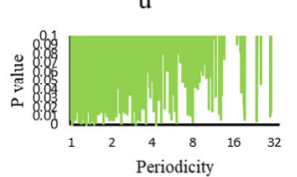

D

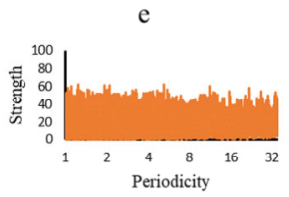

I

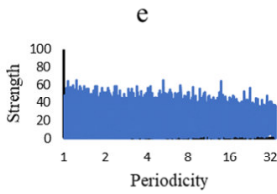

$\mathbf{N}$

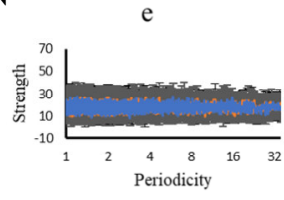

S

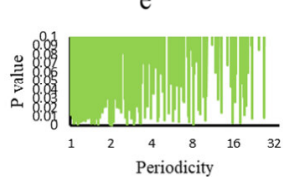

E
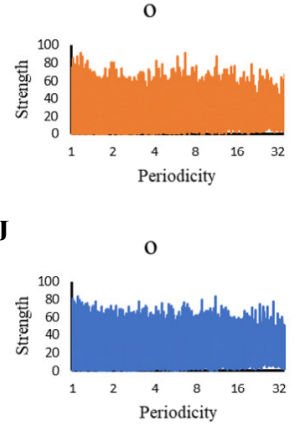

O

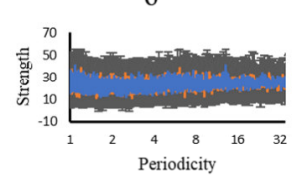

T

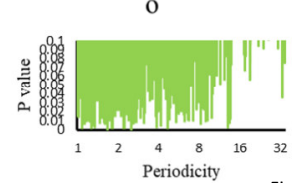

Figure 8. Fourier transform analyses of literatures by Yukio Mishima and those by Osamu Dazai, and their comparisons. (A-E) Fourier transform of the trajectories 'a', 'i', 'u', 'e' and 'o' in Yukio Mishima's literatures. Powers are plotted as a function of periodicity. (F-J) Fourier transform of the trajectories 'a', 'i', 'u', 'e' and 'o' in Osamu Dazai's literatues. Powers are plotted as a function of periodicity. (K-O) Differences in power as a function of periodicity between Mishima and Dazai. (P-T) P values obtained by the t-test between Mishima and Dazai as a function of periodicity. P-values less than 0.1 are plotted.

A

A.Conan Doyle
$\mathrm{n}=13$

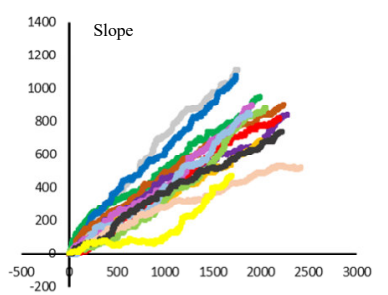

C

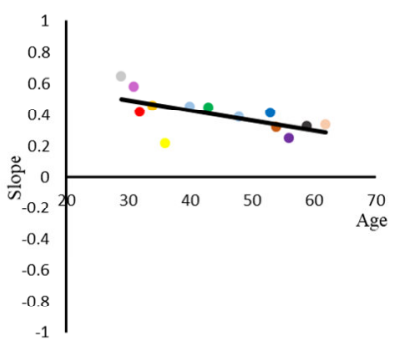

B

L.M.Montgomery $\mathrm{n}=10$

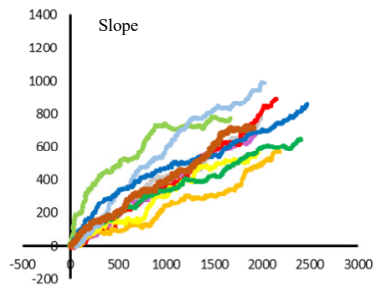

D

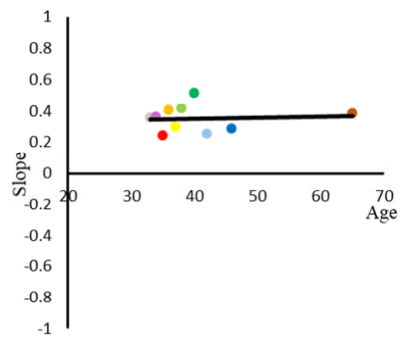

Figure 9

Figure 9. (A) Random walk patterns of literatures by Conan Doyle in English. See text for the statistical analyses. (B) Random walk patterns of literatures by Lucy Maud Montgomery in English. See text for the statistical analyses. (C) Slope of random walk pattern obtained by the linear fit is plotted as a function of the age at which the literature was written by Doyle. (D) Slope of random walk pattern obtained by the linear fit is plotted as a function of the age at which the literature was written by Montgomery. 

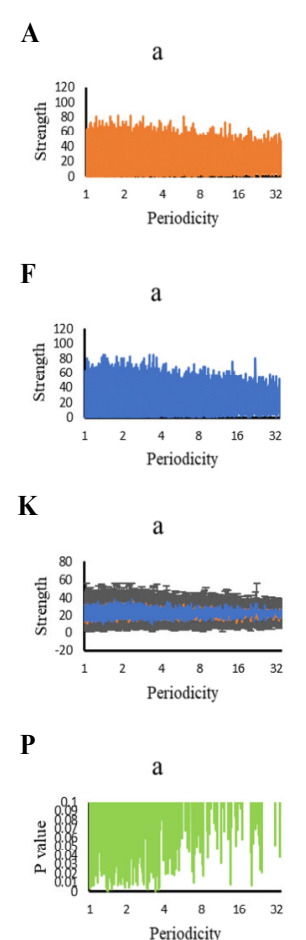

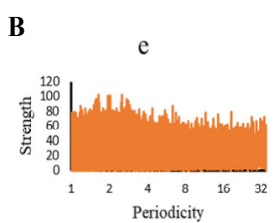

G

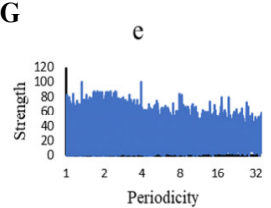

$\mathbf{L}$

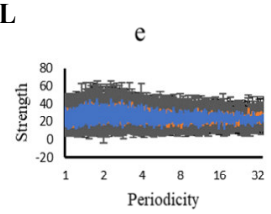

$\mathbf{Q}$

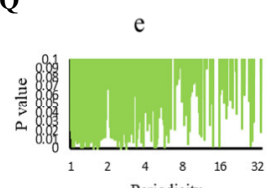

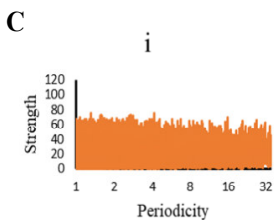

H

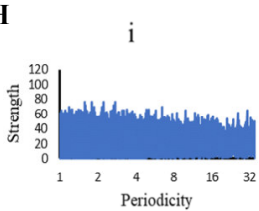

M

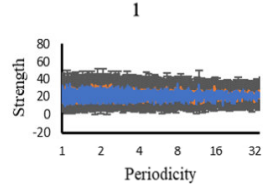

$\mathbf{R}$

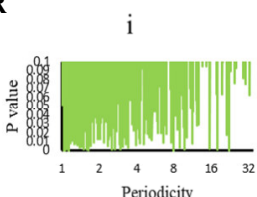

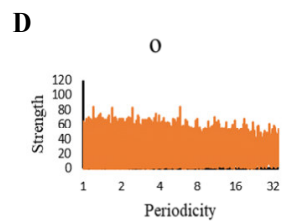

I

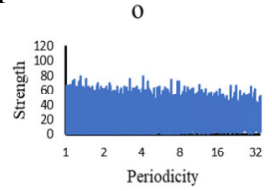

$\mathbf{N}$

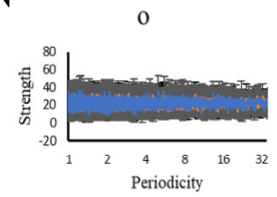

$\mathbf{S}$

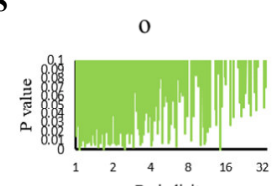

$\mathbf{E}$
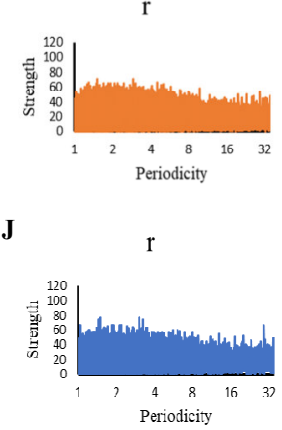

$\mathbf{O}$
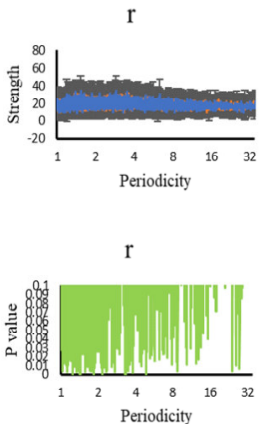

Figure 10. Fourier transform analyses of literatures written by Conan Doyle and those by Lucy Maud Montgomery in English, and their comparisons. (A-E) Fourier transform of the trajectories 'a', 'e', 'o', 'i' and 'r' in literatures by Doyle. Powers are plotted as a function of periodicity. (F-J) Fourier transform of the trajectories 'a', 'e', 'o', 'i' and ' $r$ ' in literatures by Montgomery. Powers are plotted as a function of periodicity. (K-O) Differences in power as a function of periodicity between literatures by Doyle and Montgomery. (P-T) P values obtained by the t-test between Doyle and Montgomery as a function of periodicity. P-values less than 0.1 are plotted.

\section{References}

Bedi G, Carrillo F, Cecchi GA, Slezak DF, Sigman M, Mota NB, Ribeiro S, Javitt DC, Copelli M, Corcoran CM. (2015). Automated analysis of free speech predicts psychosis onset in high-risk youths. NPJ Schizophr 1.pp.15030.

Cruz-Sandoval D, Favela J. (2019). Incorporating Conversational Strategies in a Social Robot to Interact with People with Dementia. Dement Geriatr Cogn Disord 47.pp.140-148.

Elvevag B, Foltz PW, Weinberger DR, Goldberg TE. (2007). Quantifying incoherence in speech: an automated methodology and novel application to schizophrenia. Schizophr Res 93.pp.304-316.

Fiske A, Henningsen P, Buyx A. (2019). Your Robot Therapist Will See You Now: Ethical Implications of Embodied Artificial Intelligence in Psychiatry, Psychology, and Psychotherapy. J Med Internet Res 21.pp. e13216.

Foltz PW, Rosenstein M, Elvevag B. (2016). Detecting clinically significant events through automated language analysis: Quo imus? NPJ Schizophr 2.pp.15054.

Holshausen K, Harvey PD, Elvevag B, Foltz PW, Bowie CR. (2014). Latent semantic variables are associated with formal thought disorder and adaptive behavior in older inpatients with schizophrenia. Cortex 55.pp.8896.

Kumazaki H, Warren Z, Swanson A, Yoshikawa Y, Matsumoto Y, Yoshimura Y, Shimaya J, Ishiguro H, Sarkar N, Wade J, et al. (2019). Brief Report: Evaluating the Utility of Varied Technological Agents to Elicit Social Attention from Children with Autism Spectrum Disorders. J Autism Dev Disord 49.pp.17001708.

Kuperberg GR. (2010a). Language in schizophrenia Part 1: an Introduction. Lang Linguist Compass 4.pp.576589.

Kuperberg GR. (2010b). Language in schizophrenia Part 2: What can psycholinguistics bring to the study of schizophrenia... and vice versa? Lang Linguist Compass 4.pp.590-604.

Lacan J. (1953). Some reflections on the ego. Int J Psychoanal 34.pp.11-17.

Lacan J. (1964). Le Séminaire, Livre XI. Les qartre concepts fondamentaux de la psychanalyse. ed. JaccquesAlain Miler. Paris: Seuil 
Lepoutre T, Madeira ML, Guerin N. (2017). The Lacanian Concept of Paranoia: An Historical Perspective. Front Psychol 8.pp.1564.

Manschreck TC, Merrill AM, Jabbar G, Chun J, Delisi LE. (2012). Frequency of normative word associations in the speech of individuals at familial high-risk for schizophrenia. Schizophr Res 140.pp.99103.

Mota NB, Copelli M, Ribeiro S. (2017). Thought disorder measured as random speech structure classifies negative symptoms and schizophrenia diagnosis 6 months in advance. NPJ Schizophr 3.pp.18.

Nagai N, Kuwata K, Hayashi T, Kuwata H, Era S. (2001). Evolution of the periodicity and the self-similarity in DNA sequence: a Fourier transform analysis. Jpn J Physiol 51.pp.159-168.

Pauselli L, Halpern B, Cleary SD, Ku B, Covington MA, Compton MT. (2018). Computational linguistic analysis applied to a semantic fluency task to measure derailment and tangentiality in schizophrenia. Psychiatry Res 263.pp.74-79.

Redmond JD. (2013). Contemporary perspectives on Lacanian theories of psychosis. Front Psychol 4.pp.350.

Rezaii N, Walker E, Wolff P. (2019). A machine learning approach to predicting psychosis using semantic density and latent content analysis. NPJ Schizophr 5.pp.9.

\section{Supplementary Data}

Word Salad in Japanese

Anonymous. (2012). As meaningless, incoherent soliloquy comes out, YAHOO ANSWERS. Retrieved on 5 September 2016 from https://detail.chiebukuro.yahoo.co.jp/qa/question_detail/q1087518995.

Anonymous. (2008). A Strange Letter was in the Post: Seriously Scary Story, Mysterious Net. Retrieved on 5 September 2016 from http://majikowa.blogspot.com/2012/02/1-vip20080916-183343.html.

Anonymous. (2015). Kurunchu Diary, Are you saying something that you don't understand?: Let the parties comment on the loosening of association of schizophrenia, the word salad, Hatena Blog. Retrieved on 5 September 2016 from http://kurunchu.hatenablog.com/entry/2015/10/09/171711.

Anonymous. (2018). Phrase Salad, Sigh 2 only blog. Retrieved on 11 October 2018 from http://seigi.accsnet.ne.jp/sigh/blog/?p=12622.

Anonymous. (2008). Psychiatrist Tenchan's laboratory: Both the Loosening of Association and the Flight of Ideas be Broken I, livedoor blog. Retrieved on 5 September 2016 from http://blog.livedoor.jp/psychodr10chan/archives/1011722855.html.

Anonymous. (2016). Tell me goo: Though it is normal when we meet, the mail sentence is strange. Retrieved on 24 May 2018 from https://oshiete.goo.ne.jp/qa/9402107.html.

Anonymous. (2010). The Truth of Schizophrenia: What is Schizophrenia 2. Psychologist Counselor's blog. Retrieved on 5 September 2016 from https://ameblo.jp/harmonic-soul/entry-10470791747.html.

Anonymous. (2018). With Word Salad, webkuma.net. Retrieved on 20 September 2018 from https://webkuma.net/seo/post-49078/.

Anonymous. (2014). Word Salad. A-STAR. Retrieved on 5 September 2016 from https://agencystar.com/freelance/articles/140/.

Anonymous. (2017). Word Salad: The confession of a psychiatrist, Ameba Pigg Blog. Retrieved on 24 May 2018 from https://ameblo.jp/psymiki1109/entry-12281533006.html.

Araki, T. (2005). The Possibility of Understanding of Residual Symptoms of Thought Disturbance: an Analysis of the Approach to a Chronic Schizophrenic with Severe Loosening of Association and Neologism. Bulletin of Osaka Prefecture College of Nursing, 11(1). 17-22.

Funayama, M., Kojima, T., Inaba, T., \& Kawashima, H. (2010). A Case of Neologistic Jargon Aphasia Evolving into Conduction Aphasia: Possible Mechanism of Neologism. Higher brain function Research, 30(3). 467-477.

Hara, Y., Fujimoto, S., \& Kinoshita, H. (2002). Development of nursing care for stimulant psychoticpatients: through an example of residual syndrome patients. The Japanese Psychiatric Nursing Society, 45(1). 299302.

Hayashi, K. (2011). I am funny? Sentences written by psychotic patients, Dr. Hayashi's heart and brain consultation room Highlight version. Retrieved on 5 September 2016 from https://matome.naver.jp/odai/2139390369808230601.

Hori, E. (2014). Neologism and object relation in schizophrenia. The Japanese journal of Psychoanalysis, 58(1). 31-36.

Iwanami, A. (2011). Commentary. Boku niha Sekaiga kou Mieteita: Schizophrenia Fighting Disease, by K, Kobayashi. SHINCHO BUNNKO.

kikuchi, S. (1998). The messages written by a hebephrenic patient in mutism some psychopathological features and therapeutic approaches. Japanese Journal of Psychiatric Treatment, 13(10). 1257-1264.

Kocha, H., \& Kashima, H. (2010). Neologism. Schizophrenia Frontier, 11(3). 195-200. 
Maruo. K., Takeuchi. T., Oka, H., Kuroda, K., Toyota, K., Yoneda, H., Chihara, S., \& T, Sakai. (1999). A case of tuberous sclerosis with neologism. Japanese Journal of Clinical Psychiatry, 20(10). 1559-1564.

Miyamae, O. (2016). Learning from the Psychotherapy for Schizophrenia. Bulletin of Miyagi University of Education, 50. 297-304.

Miyazato, T. (2014). You May be in a Word Salad State of Schizophrenia or Depression, Disability pension WEB for depressed people. Retrieved on 5 September 2016 from https://spartners.jp/blog/utsubyou/1513/.

Norimoto, K. (2012). Basic knowledge of psychiatric medical treatment necessary in ER: Correspondence to schizophrenia patients commentary. ER Magazine, 9(4). 561-563.

Ohara, K., Yazu, O., Nishii, R., Kokai, M., Takauchi, S., \& Morita, Y. (1999). A case of schizophrenia, Who has been mainly complained about olfactory reference syndrome during long disease's durations. Japanese Journal of Clinical Psychiatry, 28(10).1253-1261.

Saussure, F. (1959) Course in General Linguistics, New York: MacGraw-Hill

Toichi, M. (2008). Comparison of episode-type symptoms between schizophrenia and pervasive developmental disorder. Japanese journal of psychopathology, 29(3). 297-304.

Yoshida, S. (2009). I started blogging. Saori Yoshida Official Blog. Retrieved on 22 May 2018 from https://lineblog.me/yoshidasaori/archives/2009-05.html?p=11. Normal Conversation in Japanese

Arimura, K. (2013). Star man. Kasumi Arimura Official Blog. Retrieved on 22 May 2018 from https://ameblo.jp/kasumiarimura/entry-11569567921.html.

Hayashi, O. (2011). Nice to meet you. Osamu Hayashi Official Blog. Retrieved on 22 May 2018 from https://ameblo.jp/itsuyaruka/entry-11009657174.html.

Hokuto, A. (2009). Did it. There is an idiot passing through, Akira Hokuto Official Blog. Retrieved on 22 May 2018 from https://ameblo.jp/hokuto-akira/entry-10206642718.html.

Ichikawa, E. (2013). I started out why. ABKAI Official Blog. Retrieved on 22 May 2018 from https://ameblo.jp/ebizo-ichikawa/archive12-201304.html.

Imoto, A. (2009). First blog. Ayako Imoto Official Blog. Retrieved on 22 May 2018 from https://ameblo.jp/aimoto/entry-10428188824.html.

Matoba, K. (2014). Reversal of mind. Koji Matoba Official Blog. Retrieved on 22 May 2018 from https://ameblo.jp/matoba-koji/entry-11921883992.html.

Matuoka, S. (2011). Kuishinbo! Viva Kagawa Version 6. Really convey your daily thoughts! Shuzo column, Shuzo Matuoka Official Blog. Retrieved on 22 May 2018 from http://www.shuzo.co.jp/ 6 1/.

Moto, F. (2017). First time blog. One Voice of The Crane, Fuyuki Moto Official Blog. Retrieved on 22 May 2018 from https://ameblo.jp/moto-fuyuki/entry-12245124180.html.

Sakagami, S. (2009). Nice to meet you. I like beauty and what is bad, Shinobu Sakagami Official Blog. Retrieved on 22 May 2018 from https://ameblo.jp/shinobu-sakagami/.

Seto, A. (2008). Started. Asaka Seto Official Blog. Retrieved on 22 May 2018 from https://ameblo.jp/asakaseto/entry-10087.441799.html.

Tuchiya, T. (2010). Tao, Nice to Meet You. Tao's Sparkling Day, Tao Tuchiya Official Blog. Retrieved on 22 May 2018 from https://ameblo.jp/tao-tsuchiya/entry-10522173866.html.

Word Salad in English

Andreasen, N. C. (1986). The scale for assessment of thought, language and communication (TLC). Schizophrenia Bulletin, 12(3). 473-482. doi: 10.1093/schbul/12.3.473.

Anonymous. (n.d.). Formal thought disorder, Frontier Psychiatrist. Retrieved on 5 November 2017 from http://frontierpsychiatrist.co.uk/formal-thought-disorder/.

Anonymous. (2012). Letter from Charles Manson to Marilyn Manson, Redit. Retrieved on 5 November 2017 from https://www.reddit.com/r/WTF/comments/105nqr/letter from charles mans on to marilyn manson/.

Anonymous. (2014). On Word Salad. Schizophrenia and $\bar{I}$. Retrieved on 5 November 2017 from https://schizophreniaandi.wordpress.com/2014/10/14/on-word-salad/.

Anonymous. (n.d.). Schizophasia. Psychology Wiki. Retrieved on 5 November 2017 from http://psychology.wikia.com/wiki/Schizophasia.

Anonymous. (2016). Where can I find a good example of word salad as it presents in psychotic disorders? Quora. Retrieved on 5 November 2017 from https://www.quora.com/Where-can-I-find-a-good-example-ofword-salad-as-it-presents-in-psychotic-disorders.

Anonymous. (n.d.). Word Salad Examples: Word Salad on TV, Your Dictionary. Retrieved on 5 November 2017 from https://examples.yourdictionary.com/examples-of-word-salad.html.

Douglas, E. (n.d.). Achievement pressure and the word salad breakdown. Talent Development Resources, Retrieved on 5 November 2017 from http://talentdevelop.com/3442/achievement-pressure-and-the-wordsalad-breakdown/.

Edmund, P. (n.d.). A Closer Look at Psychological Disorders. Slideplayer Retrieved on 5 November 2017 from https://slideplayer.com/slide/6755079/. 
Grinnell, R. (2018). Word Salad, Psych Central. Retrieved on 1 November 2018 from https://psychcentral.com/encyclopedia/word-salad/.

Jeff, D. (2017). The Schizophrenic Sentence, The Paris Review. Retrieved on 15 November 2018 from https://www.theparisreview.org/blog/2017/12/14/the-schizophrenic-sentence/.

Kathleen, R., \& Christine, R. M. (2017). Symptoms of Schizophrenia: Topic Overview, Disorganized speech and behaviors. Cigna. Retrieved on 27 June 2018 from https:/www.cigna.com/individuals-families/healthwellness/hw/medical-topics/symptoms-of-schizophrenia-aa48032.

Maher, B. A., Manschreck, T. C., \& Molino, M. A. (1983). Redundancy, pause distributions and thoughtdisorder in schizophrenia. Language and Speech, 26. 191-199. doi: 10.1177/002383098302600207.

McKenna, P., Oh, T. (2005). Schizophrenic Speech: Making Sense of Bathroots and Ponds that Fall in Doorways. Cambridge University Press. doi: 10.1017/S003329170522603X

Rashmi, N., \& Mark, D. (n.d.). Schizophasia: Positive Symptoms of Schizophrenia, CASCADE. Retrieved on 5 November 2017 from https://www.cascadementalhealth.org/poc/view_doc.php?type=doc\&id=8809\&cn=7.

Richard, N. (n.d.). Word Salad: Examples and Observations, Thought Co. Retrieved on 5 November 2017 from https://www.thoughtco.com/word-salad-definition-1692505.Normal Conversation in English

Agatha, C. (2008). The Secret Adversary. Project Gutenberg. Retrieved on 22 May 2017 from http://www.gutenberg.org/ebooks/1155.

Charles, D. (2008). A Tale of Two Cities. Project Gutenberg. Retrieved on 22 May 2017 from http://www.gutenberg.org/ebooks/98.

Charles, D. (2014). Oliver Twist. Project Gutenberg. Retrieved on 22 May 2017 from http://www.gutenberg.org/ebooks/47529.

Graf, L. T. (2009). War and Peace. Project. Gutenberg Retrieved on 22 May 2017 from http://www.gutenberg.org/ebooks/2600.

Jacob, G., \& Wilhelm, G. (2016) Grimm's Fairy Tales. Project Gutenberg. Retrieved on 22 May 2017 from http://www.gutenberg.org/ebooks/52521.

James, M. B. (1991). Peter Pan. Project Gutenberg. Retrieved on 22 May 2017 from http://www.gutenberg.org/ebooks/16.

Jane, A. (1998). Pride and Prejudice. Project Gutenberg. Retrieved on 22 May 2017 from http://www.gutenberg.org/ebooks/1342.

Lewis, C. (1994). Alice's Adventures in Wonderland. Project Gutenberg. Retrieved on 22 May 2017 http://www.gutenberg.org/ebooks/11.

Lyman, F. B. (2008). The Wonderful Wizard of Oz. Project Gutenberg. Retrieved on 22 May 2017 from http://www.gutenberg.org/ebooks/55.

Mark, T. (2006). The Adventures of Tom Sawyer. Project Gutenberg. Retrieved on 22 May 2017 from http://www.gutenberg.org/ebooks/74.

Thomas, H. (2002). Leviathan. Project Gutenberg. Retrieved on 22 May 2017 from http://www.gutenberg.org/ebooks/3207.

Victor, H. (2008). Les Misérables. Project Gutenberg. Retrieved on 22 May 2017 from http://www.gutenberg.org/ebooks/135.

William, S. (1994). The Complete Works of William Shakespeare. Project Gutenberg. Retrieved on 22 May 2017 from Available at: http://www.gutenberg.org/ebooks/100.

Novels in Japanese

Yukio Mishima

Mishima, Y. Ao no Jidai. SHINCHO BUNKO (1971).

Mishima, Y. Bitoku no Yoromeki. SHINCHO BUNKO (1960).

Mishima, Y. Confessions of a Mask. SHINCHO BUNKO (1950).

Mishima, Y. Forbidden Colors. SHINCHO BUNKO (1964).

Mishima, Y. Kemono no Tawamure. SHINCHO BUNKO (1966).

Mishima, Y. Megami. SHINCHO BUNKO (1978).

Mishima, Y. Sizumeru Taki. SHINCHO BUNKO (1963).

Mishima, Y. Spring Snow. SHINCHO BUNKO (1977).

Mishima, Y. The Sailor Who Fell from Grace with the Sea. SHINCHO BUNKO (1968).

Mishima, Y. The Sound of Waves. SHINCHO BUNKO (1955).

Mishima, Y. The Temple of the Golden Pavilion. SHINCHO BUNKO (1956).

Mishima, Y. Tozoku. SHINCHO BUNKO (1954).

Osamu. Dazai

Dazai, O. (2000). Fairy Tales. Aozora Bunko. Retrieved on 3 March 2017 from https://www.aozora.gr.jp/cards/000035/card307.html. 
Dazai, O. (2000). Hi no tori. Aozora Bunko. Retrieved on 3 March 2017 from https://www.aozora.gr.jp/cards/000035/card268.html.

Dazai, O. (1999). Kare wa mukasi no kare narazu. Aozora Bunko. Retrieved on 3 March 2017 from https://www.aozora.gr.jp/cards/000035/card300.html.

Dazai, O. (2000). Kaze no tayori. Aozora Bunko. Retrieved on 3 March 2017 from https://www.aozora.gr.jp/cards/000035/card283.html.

Dazai, O. (2000). Kojiki gakusei. Aozora Bunko. Retrieved on 3 March 2017 from https://www.aozora.gr.jp/cards/000035/card285.html.

Dazai, O. (2002). New Hamlet. Aozora Bunko. Retrieved on 3 March 2017 from https://www.aozora.gr.jp/cards/000035/card1576.html.

Dazai, O. (1999). No Longer Human. Aozora Bunko. Retrieved on 3 March 2017 from https://www.aozora.gr.jp/cards/000035/card301.html.

Dazai, O. (2002). Right and Smile. Aozora Bunko. Retrieved on 3 March 2017 from https://www.aozora.gr.jp/cards/000035/card1577.html.

Dazai, O. (1999). Romanesuku. Aozora Bunko. Retrieved on 3 March 2017 from https://www.aozora.gr.jp/cards/000035/card316.html.

Dazai, O. (1999). Schoolgirl. Aozora Bunko. Retrieved on 3 March 2017 from https://www.aozora.gr.jp/cards/000035/card275.html.

Dazai, O. (2002). The Setting Sun. Aozora Bunko. Retrieved on 3 March 2017 from https://www.aozora.gr.jp/cards/000035/card1565.html.

Dazai, O. (1999). Villon's Wife. Aozora Bunko. Retrieved on 3 March 2017 from https://www.aozora.gr.jp/cards/000035/card2253.html.

\section{Novels in English}

Arthur Conan Doyle

Arthur, C. D. (1995). A Study in Scarlet. Project Gutenberg. Retrieved on 24 October 2017 from http://www.gutenberg.org/ebooks/244.

Arthur, C. D. (2007). Danger! and Other Stories. Project Gutenberg. Retrieved on 24 October 2017from http://www.gutenberg.org/ebooks/22357.

Arthur, C. D. (2017). Round the Fire Stories. Project Gutenberg. Retrieved on 24 October 2017 from http://www.gutenberg.org/ebooks/54109.

Arthur, C. D. (2014). The Coming of the Fairies. Project Gutenberg. Retrieved on 24 October 2017from http://www.gutenberg.org/ebooks/47506.

Arthur, C. D. (2004). The Firm of Girdle stone. Project Gutenberg. Retrieved on 24 October 2017 from http://www.gutenberg.org/ebooks/13152.

Arthur, C. D. (2003). The Green Flag and Other Stories of War and Sport. Project Gutenberg. Retrieved on 24 October 2017 from http://www.gutenberg.org/ebooks/10446.

Arthur, C. D. (2001). The Hound of the Baskervilles. Project Gutenberg. Retrieved on 24 October 2017 from http://www.gutenberg.org/ebooks/2852.

Arthur, C. D. (2008). The Lost World. Project Gutenberg. Retrieved on 24 October 2017 from http://www.gutenberg.org/ebooks/139.

Arthur, C. D. (2008). The Poison Belt. Project Gutenberg. Retrieved on 24 October 2017 from http://www.gutenberg.org/ebooks/126.

Arthur, C. D. (2004). The Refugees. Project Gutenberg. Retrieved on 24 October 2017 from http://www.gutenberg.org/ebooks/11413.

Arthur, C. D. (2000). The Sign of the Four. Project Gutenberg. Retrieved on 24 October 2017 from http://www.gutenberg.org/ebooks/2097.

Arthur, C. D. (2002). The Valley of Fear. Project Gutenberg. Retrieved on 24 October 2017 from http://www.gutenberg.org/ebooks/3289.Arthur, C. D. (1997). The White Company. Project Gutenberg. Retrieved on 24 October 2017 from http://www.gutenberg.org/ebooks/903.

Lucy Maud Montgomery

Lucy, M. M. (2006). Anne of Avonlea. Project Gutenberg. Retrieved on 24 October 2017 from http://www.gutenberg.org/ebooks/47.

Lucy, М. М. (1992). Anne of Green Gables. Project Gutenberg. Retrieved on 24 October 2017 from http://www.gutenberg.org/ebooks/45.

Lucy, M. М. (2006). Anne of the Island. Project Gutenberg. Retrieved on 24 October 2017 from http://www.gutenberg.org/ebooks/51.

Lucy, М. М. (2008). Anne's House of Dreams. Project Gutenberg. Retrieved on 24 October 2017 from http://www.gutenberg.org/ebooks/544. 
Lucy, М. М. (1998). Chronicles of Avonlea. Project Gutenberg. Retrieved on 24 October 2017 from http://www.gutenberg.org/ebooks/1354.

Lucy, M. М. (2004). Further Chronicles of Avonlea. Project Gutenberg. Retrieved on 24 October 2017 from http://www.gutenberg.org/ebooks/5340.

Lucy, M. M. (2004). Kilmeny of the Orchard. Project Gutenberg. Retrieved on 24 October 2017 from http://www.gutenberg.org/ebooks/5341.

Lucy, M. M. (2009). Rilla of Ingleside. Project Gutenberg. Retrieved on 24 October 2017 from http://www.gutenberg.org/ebooks/3796.

Lucy, M. M. (2008). The Golden Road. Project Gutenberg. Retrieved on 24 October 2017 from http://www.gutenberg.org/ebooks/316.

Lucy, M. M. (2004). The Story Girl. Project Gutenberg. Retrieved on 24 October 2017 from http://www.gutenberg.or g/ebooks/5342. 